\title{
Simultaneous Effect of Convergence and Reducing Slope of Chute Construction on the Economic of the Plan and Cavitation Index (Case Study: Daharan Dam)
}

\author{
Hesam Ghodousi' ${ }^{1}$ Amir Mahdi Abedini2* \\ ${ }^{1}$ Department of Water Engineering, University of Zanjan, Zanjan, Iran \\ ${ }^{2}$ Islamic Azad University of Kish Island, Kish Island, Iran \\ Email: *abediniamirmahdi@yahoo.com
}

Received 15 May 2016; accepted 25 July 2016; published 28 July 2016

Copyright (C) 2016 by authors and Scientific Research Publishing Inc.

This work is licensed under the Creative Commons Attribution International License (CC BY). http://creativecommons.org/licenses/by/4.0/

\section{(c) (i) Open Access}

\begin{abstract}
The Daharan Dam, like other dams, is subject to concrete surface wear or cavitation in the chute structure. This article looks into the concurrent effects of decreasing the chute angle and slope profile changes from a single slope to a double slope and the simultaneous latitudinal convergence of the chute structure on the cavitation index and the economy of project. In order to perform this research, the geometric specifications were collected of the dam, and the chute structure as well as those of a flood with a return period of $\mathbf{1 0 0 0}$ years, which make up the basis of the spillway design. Taking advantage of the numerical WS77 model, different modes were simulated with a single slope, double slope with fixed latitude, double slope with latitudinal convergence, and the cavitation index and the excavation volumes for each option were calculated. The results indicated that a decrease in slope led to a rise in the cavitation index to over $\mathbf{1 . 2}$ and that the convergence of the chute structure positively affected the increase in the cavitation index.
\end{abstract}

\section{Keywords}

Cavitation, Chute Structure, WS77 Model, Latitudinal Convergence of Chute

\section{Introduction}

In the light of the current issues and the ongoing discussions about the shortage of water resources and deepening *Corresponding author.

How to cite this paper: Ghodousi, H. and Abedini, A.M. (2016) Simultaneous Effect of Convergence and Reducing Slope of Chute Construction on the Economic of the Plan and Cavitation Index (Case Study: Daharan Dam). Open Journal of Geology, 6, 617-625. http://dx.doi.org/10.4236/ojg.2016.67048 
drought in the country, dam construction has become a key issue which has drawn the attention of experts and officials. There are currently around 1000 dams in the country which are either under study or construction, or are already in operation. One of the main structures in dams is the chute structure, which functions as an outlet to empty flash floods from the dam's reservoir and to reduce the pressure against the body of the dam. In the design of spillovers, a problematic phenomenon that needs to be studied and addressed is cavitation. Cavitation occurs when the concrete surface is eroded and the dam sustains serious damage. Thus knowledge of this phenomenon and preventing it are fundamental issues that should be considered in the construction of dams. In order to avoid cavitation in the Daharen Dam, instead of constructing the chute structure with a single slope, the slope profile of the chute structure was designed with double slope. In addition, the width of the chute structure decreases downwards. In a research entitled "Effect of Entrained Air on Cavitation Damage" Sheehan writes: experiments conducted by Petcrka proved that aeration effectively reduces damage caused by cavitation. Since the beginning of the aeration process in the Grand Coulee Dam in 1952, the technology has been widely used to empty high dams. The behavior, mechanism and use of aeration for controlling cavitation have been under study for more than half a century. Although certain cavitation-related damage has occurred in the presence of comprehensive aeration, the efficiency of the technology depends on a wide range of factors, including geophysical and hydraulic parameters as well as aeration methods. In this study, the laboratory environment for the aeration was closely designed and the behavior reducing the cavitation-related damage was investigated from three different aspects. The result of the survey indicated that the decrease in the damage caused by cavitation is largely dependent on the number of airways, the pressure and location of aeration. In a 2007 research entitled "Cavitation characteristics of high velocity flow with and without aeration on the order of $50 \mathrm{~m} / \mathrm{s}$ ", Zhi-yong Dong et al. stated that experimental study of cavitation characteristics with and without aeration was conducted at the flow velocity 50 $\mathrm{m} / \mathrm{s}$ in the non-circulating type water tunnel in the Hydraulics Laboratory at Zhejiang University of Technology. Variations of pressure and cavitation number with air concentration, pressure waveforms as well as cavitation erosion level of concrete specimen with and without aeration were obtained. The effects of cavitation control by aeration were analyzed.

Experience has shown that the high velocity of water flow on the surface of spillovers can lead to cavitationrelated corrosion. A deviation in the water flow lines as well as bumpy and uneven concrete surface made during the construction process and afterwards can decrease the pressure in some areas. If this low temperature reaches the evaporation threshold the cavitation phenomenon will take place. It is noteworthy that utilizing high-strength concrete, which to a large extent prevents damage caused by high velocity, will not be able to stop the resulted damage if cavitation takes place. The goal of this research is probing a unique method which was used in the Daharan Dam to control cavitation. In this method, a double slope chute structure was used instead of a single slope and the structure converged in latitude (Table 1).

After determining the latitude of the spillway using the general formula of the flow through the spillway $(\mathrm{Q}=$ flow, $\mathrm{L}=$ spillway crest width, $\mathrm{H}=$ elevation difference between the reservoir water surface and the spillway crest) the stage-discharge relationship of the spillway was established in order to determine the stage-discharge relation or the rating curve, which is demonstrated in Diagram 1 and Table 2.

As mentioned above, the amounts of discharge flow through the spillway following routing or spreading of flood waters was used in the design of the spillway and the chute in the Daharan dam.

\begin{tabular}{cc} 
Table 1. General specifications of Daharan storage dam. \\
\hline 54.5 & Floor elevation at dam axis (meters above sea level) \\
80.5 & Elevation of crown (meters above sea level) \\
76 & Normal operating elevation of full reservoir (meters above sea level) \\
26.5 & Total volume of reservoir in normal operation elevation (million cubic meters) \\
6.2 & Dead storage volume (million cubic meters) \\
19.93 & Active storage volume in normal operation elevation (million cubic meters) \\
255 & Crown length (meter) \\
26 & Height of dam above valley floor (meter) \\
\hline
\end{tabular}


Table 2. Quantity of discharge and storage input/output.

\begin{tabular}{cccc}
\hline PMF & 10,000 & 1000 & Flood return period \\
327 & 134 & 94 & Maximum of output flow $\left(\mathrm{m}^{3} / \mathrm{s}\right)$ \\
1380 & 753 & $\mathrm{~T} 551$ & Maximum of input flow $\left(\mathrm{m}^{3} / \mathrm{s}\right)$ \\
75.75 & 73.23 & 72.57 & Maximum elevation of water \\
1053 & 619 & 457 & Difference between the input flow and output flow \\
\hline
\end{tabular}

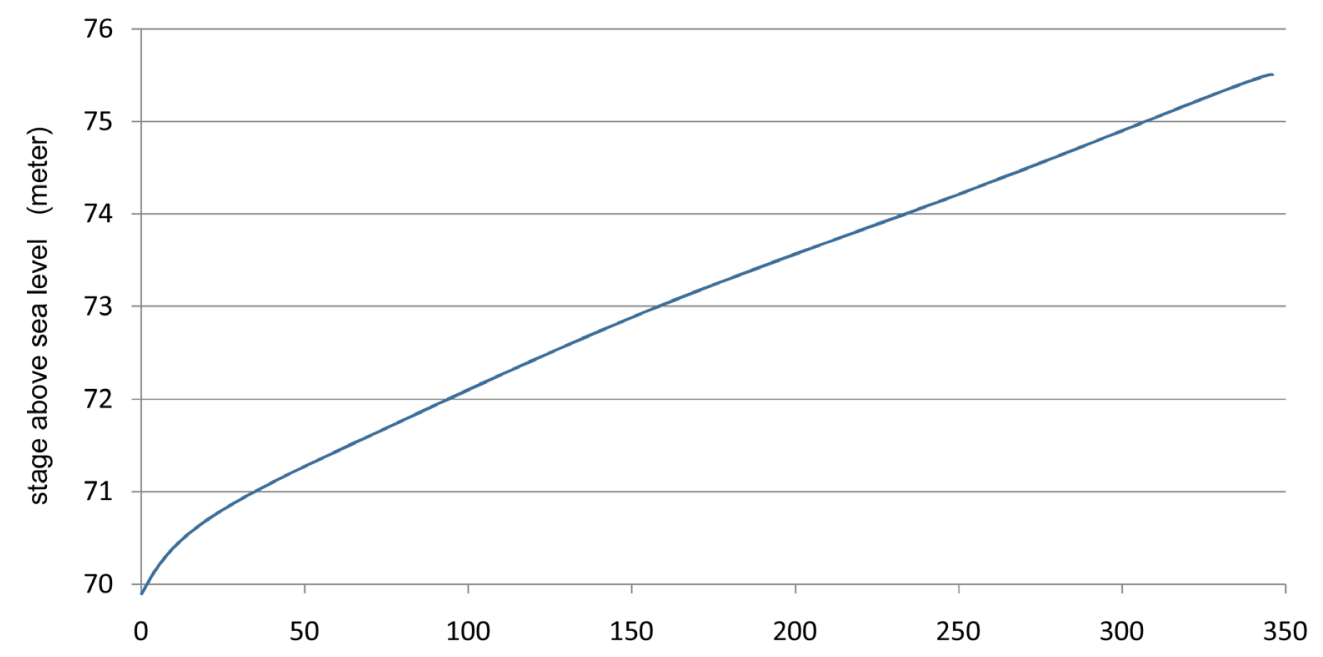

Diagram 1. Stage-discharge curve.

\section{Introducing WS77 Numerical Model}

WS77 is a one-dimensional program which was designed by the United States Bureau of Reclamation (USBR) in 1990 and is used to simulate some hydraulic parameters on spillways and tunnels for bottom outlets. In fact this program is used for an initial estimate of the hydraulic parameters. By calculating the cavitation indices and comparing it with the critical cavitation indices in this program cavitation could be predicted.

WS77 which stands for Water surface is based on determining the water surface profile through a standard step method, which is used for gradually varied flow in prismatic channels. The output of this program includes all hydraulic parameters and cavitation specifications [1].

\section{Cavitation-Linked Equations}

In many cases, it is impossible to calculate the surface velocity and thus mathematical models are utilized to examine the occurrence of the cavitation phenomenon. In simulating this phenomenon parameters that lead to cavitation must be replicated, thus, a dimensionless parameter has been defined in the name of cavitation index which is as follows:

$$
\frac{\text { force causing cavitation }}{\text { force preventing cavitation }}=\frac{\text { inertial force }}{\text { compressive force }}=\frac{1}{\mathrm{NE}}
$$

The net pressure that causes cavitation is $p_{0}-p_{v}$, in which $p_{v}$ vapor pressure and $p_{0}$ is the liquid pressure at a certain points. The inertial force is also $\frac{1}{2} \rho v_{0}^{2}$ therefore

$$
\sigma=\frac{P_{0}-P_{v}}{\frac{1}{2} \rho V_{0}^{2}}=\frac{\frac{P_{0}}{\gamma}-\frac{P_{v}}{\gamma}}{\frac{V_{0}^{2}}{2 g}}
$$


In case of a vertical arc at the bottom the following equation is used:

$$
\sigma=\frac{\frac{P_{0}}{\gamma}+h \cos \alpha+\frac{h * v^{2}}{g * r}-\frac{P_{v}}{\gamma}}{\frac{V_{0}^{2}}{2}}
$$

Based on the Falvey's research results, the following equation is used to calculate the single roughness of the cavitation index:

$$
V_{i}=\frac{h-h_{v}}{\frac{V_{0}^{2}}{2 g}}
$$

in which $h$ is a height equal to the absolute pressure, $h_{v}$ the vapor pressure height, and $V_{0}$ is the velocity near the point over the roughness. Earnst shows that the cavitation can occur on a surface with uniform roughness, and using the Darcy-Weisbach friction quotient presented the equation below [2]

$$
v_{i}=4 f
$$

In the Formula (2), $P_{0}$ is absolute pressure and $P_{v}$ is vapor pressure at $20^{\circ}$ Celsius and $V$ is velocity of the flow. If the vapor pressure at the given temperature is equal to an 8.92-meter water column, the following equation will be resulted:

$$
\sigma=\frac{\frac{\rho}{\gamma}+\frac{P_{a t m}}{\gamma}-0.123}{\frac{V^{2}}{2 g}}
$$

\section{Chute Structure with Single Slope}

As illustrated in Figure 1, in this form, the slope of the chute structure is steady and in one line from the end of the spillway channel to the stilling basin. In this case, the structure stretches from a height of 76 meters above sea level to 46.93 meters at the bed of the basin on a 24.76 percent slope. This was modeled in the WS77 program so that the cavitation index could be determined. The model's outputs under 1000-year floodwaters a-re listed in Table 3. This was also modeled by the use of Auto Cad software and for each 5-meter interval from the first station (the start point of the rapids channel) they were a cross-section was considered. The floor of the channel was considered as the base level and the volume of the earthwork excavation was calculated according to the width of the structure and the distance from the natural ground line. Consequently the results were classified in Microsoft Excel, as demonstrated in Table 4.

Distance parameter between sections in the original version calculated as "distance +5 meters" format in to

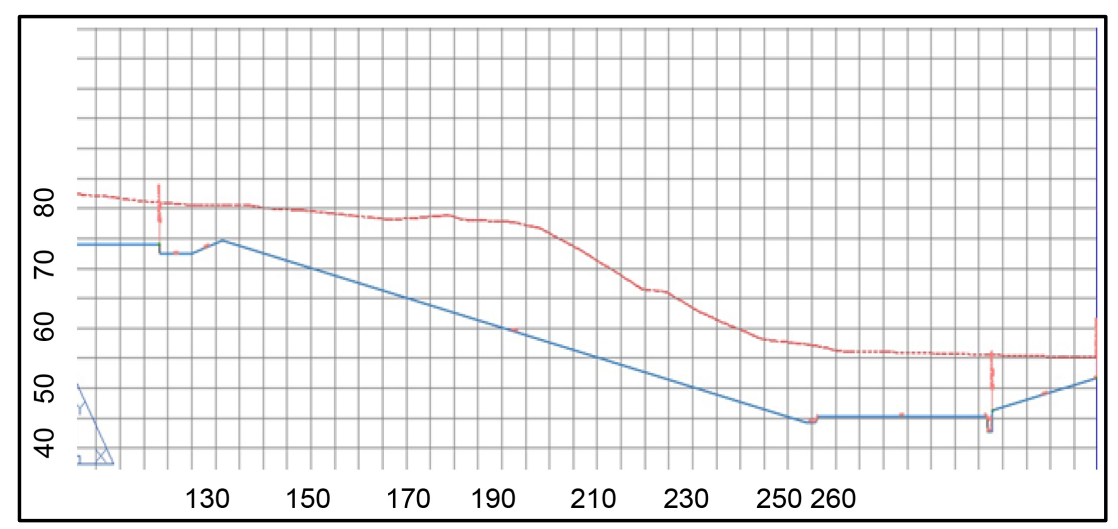

Figure 1. Profile of single slope chute structure. 
Table 3. WS77 outputs in single-slope mode. $\mathrm{Q}=551 \mathrm{CMS}$. Rugosity $=0.8 \mathrm{~mm}, \mathrm{~N}=0.014$.

\begin{tabular}{|c|c|c|c|c|c|}
\hline Station (m) & Invert Depth (m) & With & Depth (m) & Velocity (m/s) & Flow Sigma \\
\hline 0 & 76 & 22 & 2.41 & 10.13 & 9.11 \\
\hline 3.5 & 75.22 & 22 & 2.40 & 10.58 & 8.01 \\
\hline 10 & 73.745 & 22 & 2.40 & 11.00 & 7.11 \\
\hline 20 & 71.46 & 22 & 2.35 & 11.32 & 6.50 \\
\hline 30 & 69.205 & 22 & 2.30 & 11.67 & 5.88 \\
\hline 35 & 68.08 & 22 & 2.24 & 12.02 & 5.32 \\
\hline 40 & 66.95 & 22 & 2.20 & 12.33 & 4.87 \\
\hline 45 & 65.56 & 22 & 2.20 & 12.63 & 4.46 \\
\hline 50 & 64.695 & 22 & 2.19 & 12.93 & 4.08 \\
\hline 55 & 63.575 & 22 & 2.18 & 13.23 & 3.73 \\
\hline 60 & 62.44 & 22 & 2.11 & 13.34 & 3.61 \\
\hline 65 & 61.32 & 22 & 2.10 & 13.46 & 3.48 \\
\hline 70 & 60.185 & 22 & 2.10 & 13.91 & 3.05 \\
\hline 70.97 & 59.975 & 22 & 2.00 & 14.24 & 2.76 \\
\hline 77.93 & 58.405 & 22 & 1.99 & 14.50 & 2.20 \\
\hline 80 & 57.93 & 22 & 1.97 & 14.71 & 1.95 \\
\hline 82.27 & 57.419 & 22 & 1.93 & 14.86 & 1.20 \\
\hline 90 & 55.675 & 22 & 1.92 & 14.96 & 0.91 \\
\hline 93.18 & 54.957 & 22 & 1.92 & 15.01 & 0.75 \\
\hline 100 & 53.425 & 22 & 1.90 & 15.02 & 0.42 \\
\hline 104.16 & 52.486 & 22 & 1.89 & 16.52 & 0.32 \\
\hline 107.39 & 51.757 & 22 & 1.85 & 17.77 & 0.24 \\
\hline 110 & 51.17 & 22 & 1.80 & 18.05 & 0.18 \\
\hline 112.93 & 50.5 & 22 & 1.18 & 18.69 & 0.15 \\
\hline 120 & 48.915 & 22 & 1.15 & 19.11 & 0.11 \\
\hline 128.9 & 46.93 & 22 & 1.13 & 19.49 & 0.09 \\
\hline
\end{tabular}

reduce the number of rows in the paper, use "distance +10 meter" format. That's why the number shown in tables for excavation about cumulative volume does not match.

\section{Chute Structure with Two Slopes}

As illustrated in Figure 2, the slope profile of the slope in the chute structure runs for 65 meters from the start of the rapids channel with a slight slope of 4 percent and then runs on a 47.9 percent slope for 60 meters before it reaches the stilling basin. As in a single slope mode, the current structure was modeled with the use of W77 and the results are demonstrated in Table 5. The volume of the earthwork excavation in this mode can also been seen in Table 6.

\section{Converging Double-Slope Chutes}

In this mode, in addition to incorporating two slopes across the chute, there is also a reduction in the width of the rapids channel. At the opening, the rapids channel measures 22 meters in width and 76 meters (above sea level) in height; then the chute gradually shrinks in width to 14 meters. Having stretched for nearly 60 meters, this 
Table 4. Excavation volume in single-slope mode.

\begin{tabular}{cccc}
\hline Distance & Excavation area & Excavation volume & Cum. Vol of excavation \\
\hline (Meter) & $($ sq.m) & $($ Cu.m. $)$ & (Cu.m.) \\
$0+0.00$ & 566.75 & 2608.21 & 2608.21 \\
$0+10.00$ & 583.48 & 2902.83 & 8372.05 \\
$0+20.00$ & 598.15 & 2969.75 & $14,274.87$ \\
$0+30.00$ & 613.77 & 3048.24 & $20,332.31$ \\
$0+40.00$ & 592.99 & 2996.53 & $26,377.31$ \\
$0+50.00$ & 562.34 & 2855.74 & $32,165.42$ \\
$0+60.00$ & 564.57 & 2811.87 & $37,783.58$ \\
$0+70.00$ & 437.43 & 2469.86 & $43,041.14$ \\
$0+80.00$ & 355.93 & 1875.04 & $46,994.98$ \\
$0+90.00$ & 297.81 & 1510.09 & $50,160.45$ \\
$0+100.00$ & 251.46 & 1348.28 & $52,979.2$ \\
$0+110.00$ & 185.45 & 99.82 & $55,129.57$ \\
$0+120.00$ & 161.1 & 821.86 & $56,832.88$ \\
$0+130.00$ & 155.41 & 788.34 & $58,425.07$ \\
\hline
\end{tabular}

Table 5. WS77 outputs in double-slope, fixed-width chutes. Q-551 CMS. Rugosity = $0.8 \mathrm{~mm}, \mathrm{~N}=0.014$.

\begin{tabular}{|c|c|c|c|c|c|}
\hline Station (m) & Invert Depth (m) & With & Depth (m) & Velocity (m/s) & Flow Sigma \\
\hline 0 & 76 & 22 & 2.97 & 8.7315 & 9.561 \\
\hline 3.5 & 75.31 & 22 & 2.961 & 9.1823 & 8.458 \\
\hline 10 & 75.01 & 22 & 2.955 & 9.5986 & 7.563 \\
\hline 20 & 74.71 & 22 & 2.91 & 9.9183 & 6.948 \\
\hline 30 & 74.41 & 22 & 2.861 & 10.2679 & 6.331 \\
\hline 35 & 74.28 & 22 & 2.801 & 10.6175 & 5.773 \\
\hline 40 & 74.13 & 22 & 2.761 & 10.9257 & 5.319 \\
\hline 45 & 73.98 & 22 & 2.758 & 11.2316 & 4.906 \\
\hline 50 & 73.83 & 22 & 2.754 & 11.5329 & 4.528 \\
\hline 55 & 73.63 & 22 & 2.742 & 11.8342 & 4.178 \\
\hline 60 & 73.47 & 22 & 2.665 & 11.9354 & 4.06 \\
\hline 65 & 73.41 & 22 & 2.661 & 12.0642 & 3.93 \\
\hline 70 & 73.15 & 22 & 2.66 & 12.5081 & 3.203 \\
\hline 70.97 & 73.11 & 22 & 2.558 & 12.8439 & 3.008 \\
\hline 77.93 & 71.43 & 22 & 2.551 & 13.1015 & 2.35 \\
\hline 82.27 & 69.35 & 22 & 2.5251 & 13.3131 & 1.91 \\
\hline 93.18 & 64.12 & 22 & 2.492 & 13.4557 & 1.05 \\
\hline 104.16 & 58.85 & 22 & 2.481 & 13.5615 & 0.96 \\
\hline 107.39 & 57.3 & 22 & 2.48 & 13.6121 & 0.65 \\
\hline 110 & 56.05 & 22 & 2.46 & 13.619 & 0.47 \\
\hline 112.93 & 55.39 & 22 & 2.452 & 15.1163 & 0.37 \\
\hline 120 & 52.67 & 22 & 2.411 & 16.3721 & 0.29 \\
\hline 128.83 & 46.93 & 22 & 2.36 & 16.6504 & 0.23 \\
\hline
\end{tabular}


Table 6. Calculating excavation volume in double-slope, fixed-width chutes.

\begin{tabular}{cccc}
\hline Distance & Excavation area & Excavation volume & Cum. Vol of excavation \\
\hline (meter) & (Sq.m.) & $($ Cu.m. & $($ Cu.m.) \\
$0+0.000$ & 182.08 & 951.47 & 951.47 \\
$0+10.000$ & 215.94 & 1008.85 & 2838.66 \\
$0+20.000$ & 304.8 & 1442.86 & 5912.13 \\
$0+30.000$ & 395.4 & 1898.43 & 9444.27 \\
$0+40.000$ & 404.66 & 1939.2 & $13,330.8$ \\
$0+50.000$ & 449.54 & 2216.29 & $17,626.3$ \\
$0+60.000$ & 495.82 & 2414.27 & $22,348.9$ \\
$0+70.000$ & 418.27 & 2316.22 & $27,200.2$ \\
$0+80.000$ & 369.85 & 1903.8 & $31,149.8$ \\
$0+90.000$ & 336.69 & 1663.94 & 4511.6 \\
$0+100.000$ & 329.88 & 1709.39 & $37,931.87$ \\
$0+110.000$ & 290.66 & 1486.69 & $40,985.69$ \\
$0+120.000$ & 296.26 & 1448.53 & $43,884.93$ \\
$0+130.000$ & 275.91 & 1020.55 & $46,834.91$ \\
\hline
\end{tabular}

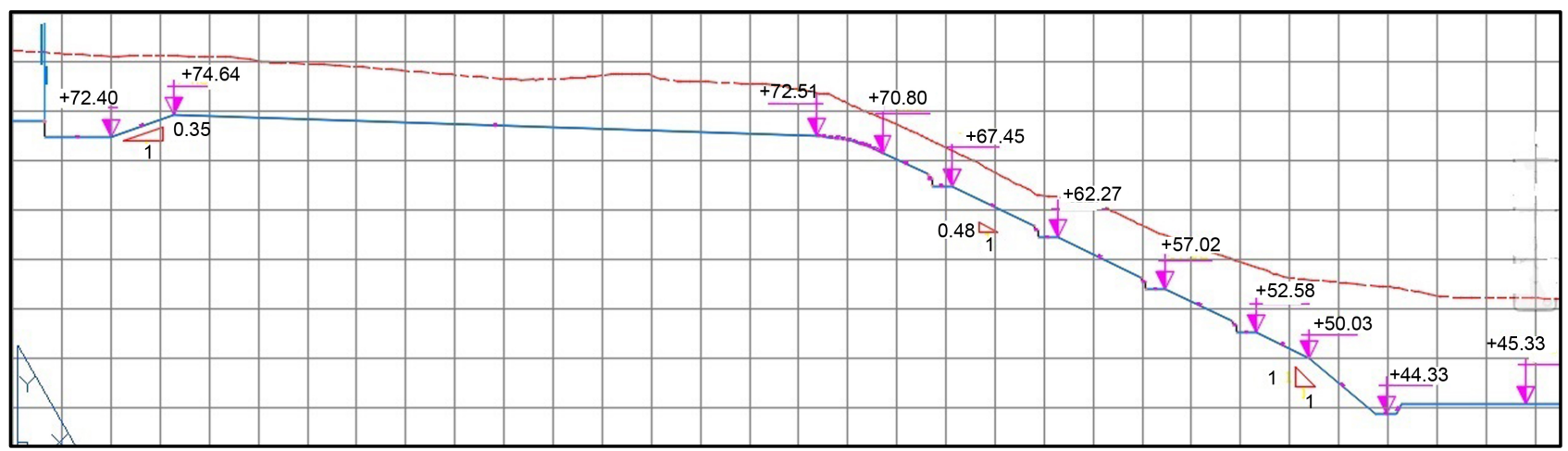

Figure 2. Profile of 2 slope chute structure.

channel rises to a height of 73.11 and then declines to 46.93 meters on a 47.9 percent slope. Like previous modes, this was also modeled with the help of WS77 program and the outputs are demonstrated in Table 7. The volume of the excavation operation can also be seen in Table 8.

\section{Comparing Cavitation Indices in Single and Double-Slope Modes}

The summarized results of the WS77 outputs can be seen in Table 9. As illustrated in the table, the change in the slope from the single to the double-slope mode and the converging width of the chute structure has raised the cavitation index.

In 1983, Falvey proposed a series of criteria to prevent the damage caused by cavitation, which can be seen in Table 10. According to Table 10, it can be concluded that in the converging double-slope mode that the structure is needless of protection against cavitation-liked problems.

\section{Economic Comparison of Single Slope, Fixed-Width Double Slope and Converging Double Slope Modes}

As mentioned earlier, in order to decrease the excavation volume for the chute structure in the Daharan Dam, instead of constructing a single slope structure, two slopes were incorporated in the length of the structure. That means water initially flows on a slight 4 percent slope and after running 60 meters reaches a steeper slope of 
Table 7. WS77 outputs in converging, double-slope mode. $\mathrm{Q}=551 \mathrm{CMS}$. Rugosity $=0.8 \mathrm{~mm}, \mathrm{~N}=0.014$.

\begin{tabular}{|c|c|c|c|c|c|}
\hline Station (m) & Invert Depth (m) & With & Depth (m) & Velocity (m/s) & Flow Sigma \\
\hline 0 & 76 & 22 & 2.97 & 8.732 & 9.561 \\
\hline 3.5 & 75.31 & 22 & 2.96 & 9.182 & 8.458 \\
\hline 10 & 75.01 & 22 & 2.96 & 9.599 & 7.563 \\
\hline 20 & 74.71 & 22 & 2.91 & 9.918 & 6.948 \\
\hline 30 & 74.41 & 22 & 2.86 & 10.268 & 6.331 \\
\hline 35 & 74.28 & 22 & 2.80 & 10.618 & 5.773 \\
\hline 40 & 74.13 & 20.97 & 2.90 & 9.942 & 5.851 \\
\hline 45 & 73.98 & 19.86 & 2.90 & 10.221 & 5.397 \\
\hline 50 & 73.83 & 19.2 & 2.89 & 10.495 & 4.981 \\
\hline 55 & 73.63 & 18 & 2.88 & 10.769 & 4.596 \\
\hline 60 & 73.47 & 18 & 2.80 & 10.861 & 4.466 \\
\hline 65 & 73.41 & 18 & 2.79 & 10.978 & 4.323 \\
\hline 70 & 73.15 & 18 & 2.79 & 11.382 & 3.523 \\
\hline 70.97 & 73.11 & 18 & 2.69 & 11.688 & 3.309 \\
\hline 77.93 & 71.43 & 18 & 2.68 & 11.922 & 2.585 \\
\hline 82.27 & 69.35 & 17.4 & 2.65 & 12.115 & 2.101 \\
\hline 93.18 & 64.12 & 15.96 & 2.62 & 12.245 & 1.155 \\
\hline 104.16 & 58.85 & 14.48 & 2.61 & 12.341 & 1.056 \\
\hline 107.39 & 57.3 & 14 & 2.60 & 12.387 & 0.715 \\
\hline 110 & 56.05 & 14 & 2.58 & 12.393 & 0.564 \\
\hline 112.93 & 55.39 & 14 & 2.57 & 13.756 & 0.444 \\
\hline 120 & 52.67 & 14 & 2.53 & 14.899 & 0.348 \\
\hline 128.83 & 46.93 & 14 & 2.48 & 15.152 & 0.321 \\
\hline
\end{tabular}

Table 8. Calculating excavation volume in converging, double-slope mode.

\begin{tabular}{cccc}
\hline Distance & Excavation area & Excavation volume & Cum. Vol of excavation \\
\hline (meter) & $($ Sq.m. $)$ & $($ Cu.m. $)$ & (Cu.m.) \\
$0+0.00$ & 182.08 & 951.47 & 951.47 \\
$0+10.00$ & 215.94 & 1008.55 & 2838.66 \\
$0+20.00$ & 268.96 & 272.81 & 5251.74 \\
$0+30.00$ & 325.72 & 1562.01 & 8233.85 \\
$0+40.00$ & 364.41 & 1781.84 & $11,700.32$ \\
$0+50.00$ & 391.18 & 1930.09 & $15,494.07$ \\
$0+60.00$ & 432.89 & 2107.33 & $19,604.45$ \\
$0+70.00$ & 364.4 & 2017.15 & $23,809.97$ \\
$0+80.00$ & 320.12 & 1651.12 & 27,223 \\
$0+90.00$ & 293.27 & 1451.12 & $30,192.37$ \\
$0+100.00$ & 281.97 & 1460.8 & $33,142.22$ \\
$0+110.00$ & 245.29 & 1256 & $35,745.92$ \\
$0+120.00$ & 254.6 & 1243.24 & $38,209.12$ \\
$0+130.00$ & 225.03 & 835,64 & $40,697.48$ \\
\hline
\end{tabular}


Table 9. Comparison of cavitation indices under 1000-year floodwaters (with a return period of 1000 years) in different.

\begin{tabular}{cccc}
\hline Converging double slope & Double slope with fixed width & Single slope & \\
\hline 9.561 & 9.561 & 8.31 & Max cavitation index under 1000 year floodwaters \\
8.961 & 8.961 & 9.11 & Max cavitation index under 10,000 year floodwaters \\
0.45 & 0.23 & 0.01 & Min cavitation index under 1000 year floodwaters \\
0.31 & 0.19 & 0.01 & Min cavitation index under 10,000 year floodwaters \\
\hline
\end{tabular}

Table 10. Falvey criteria.

\begin{tabular}{|c|c|}
\hline Cavitation number $\sigma$ & Design requirements \\
\hline$>1.80$ & No cavitation protection is required \\
\hline $0.25-1.80$ & The flow surface can be protected by flow surface treatment (e.g. smoothing all surface roughness) \\
\hline $0.17-0.25$ & Modification of the design (e.g. increasing boundary curvature) \\
\hline $0.12-0.17$ & Protection by addition of aeration grooves or steps \\
\hline$<0.12$ & Surface cannot be protected and a different configuration is required (assumption) \\
\hline
\end{tabular}

47.90 percent where it enters the stilling basin at $130 \mathrm{~km}$. Meanwhile, the chute structure gradually shrinks in width and leads to a remarkable decrease in the excavation volume, which, needless to say, reduces the economic costs in turn.

\section{Conclusions}

According to the research and studies performed, and a case study of the Daharan dam, the following results were concluded:

1) By changing the slope of the chute structure from single slope to double slope mode, the cavitation number falls within the range of the Falvey criteria and this cavitation phenomenon does not occur. Thus, there will be no need for the use of expensive procedures required to deal with cavitation and economic costs will be reduced naturally.

2) The convergence in the width of the chute structure reduces the volume of excavation and increases the cavitation index.

3) The change from a single steep slope in the chute structure to a mix of a slight and a steep slope results in a significant decrease in the volume of excavation. Obviously, reducing the amount of excavation cuts the economic costs.

\section{References}

[1] Akbari, G. (2012) A Survey of the Cavitation Phenomenon on Minab Dam Spillway. 11 $1^{\text {th }}$ Conference of Hydraulics in Iran, Orumie University, October 2012, 2.

[2] Foroudi, A., Sanei, M. and Ajdari-Moghaddam, M. (2014) A Laboratory Study of Cavitation Index Changes in Ogee Spillway with Arch in Plan and Converging Spillway Walls. 8th National Congress on Civil Engineering, Babol Noshirvani University of Technology, April 2014, 4. 


\section{Submit or recommend next manuscript to SCIRP and we will provide best service for you:}

Accepting pre-submission inquiries through Email, Facebook, LinkedIn, Twitter, etc.

A wide selection of journals (inclusive of 9 subjects, more than 200 journals)

Providing 24-hour high-quality service

User-friendly online submission system

Fair and swift peer-review system

Efficient typesetting and proofreading procedure

Display of the result of downloads and visits, as well as the number of cited articles

Maximum dissemination of your research work

Submit your manuscript at: http://papersubmission.scirp.org/ 